\title{
Erratum to: Methods of Electron Microdiffraction and X-Ray Analysis in Structure Study of Nanodisperse Partially Stabilized $\mathrm{ZrO}_{2}$ Powders
}

\author{
N. A. Zaporina ${ }^{a, *}$, O. A. Doynikova ${ }^{b}$, A. P. Krumina ${ }^{a}$, D. V. Bocharov ${ }^{c}$, and J. P. Grabis ${ }^{a}$ \\ ${ }^{a}$ Institute of Inorganic Chemistry, Riga Technical University, 34 Miera str., Salaspils, 2169 Latvia \\ ${ }^{b}$ Institute of Ore Deposits Geology, Petrography, Mineralogy, and Geochemistry, Russian Academy of Sciences, \\ Staromonetnyi per. 35, Moscow, 109017 Russia \\ ${ }^{c}$ Institute of Solid State Physics, University of Latvia, Kengaraga str. 8, Riga, 1063 Latvia \\ *e-mail: bocharov@latnet.lv \\ Submitted April 16, 2019; accepted for publication April 16, 2019
}

DOI: $10.1134 / \mathrm{S} 1027451019030376$

The name of the fourth author should read $D . V$. Bocharov.

The original article can be found online at https://doi.org/10.1134/S1027451009030227. 